\title{
Accuracy of aortic pulse wave velocity assessment with velocity-encoded MRI: validation in patients with Marfan syndrome
}

\author{
Eleanore S Kröner ${ }^{1}$, Rob J van der Geest ${ }^{1}$, Arthur J Scholte ${ }^{1}$, Pieter J van den Boogaard ${ }^{1}$, \\ Dennis Hendriksen ${ }^{1}$, Lucia J Kroft ${ }^{1}$, Maarten Groenink², Teodora Radonic ${ }^{2}$, Jeroen J Bax', Albert de Roos', \\ Johan H Reiber ${ }^{1}$, Jos J Westenberg ${ }^{1 *}$
}

From 2011 SCMR/Euro CMR Joint Scientific Sessions

Nice, France. 3-6 February 2011

\section{Introduction}

The leading cause of premature death in patients with Marfan syndrome (MFS) is aortic dissection and subsequent rupture after progressive aorta dilatation due to increased wall stiffening. Pulse Wave Velocity (PWV), defined as the systolic flow velocity wave front propagation speed through the aorta, is a marker of wall stiffness with proven prognostic value in MFS. Recently it was demonstrated that, although time-consuming, PWV-assessment from two-directional in-plane velocityencoded MRI covering the whole aorta in three parallel oblique-sagittal slices is the most accurate approach (1). 2 -slice free-breathing through-plane velocity-encoded MRI at three locations perpendicular to the aorta (2) is traditionally used for PWV-estimation. Accelerated multi-slice acquisition with breath-holding and moredensed sampling along the aorta might improve accuracy.

\section{Purpose}

To examine accuracy of PWV-assessment from 2-slice free-breathing and 4-slice breath-held through-plane velocity-encoded MRI in MFS.

\section{Methods}

Eighteen MFS patients ( 9 men, mean age $=33 \pm 12$ years) were included. PWV-assessment was performed on 1.5T MRI (Philips Medical Systems, Best, the Netherlands). Three methods were evaluated; 1 ) reference standard: two-directional in-plane velocity-encoding with high temporal resolution $=9 \mathrm{~ms}$ in three parallel oblique-sagittal slices covering the whole aorta, sampling PWV at 200 equidistant points along the aorta; 2) traditional 2-slice method: two free-breathing through-plane velocity-encoded acquisitions with high temporal resolution $=10 \mathrm{~ms}$ at the proximal aorta transecting ascending and proximal descending aorta and at the abdominal aorta; 3) accelerated 4-slice method: four breath-held velocity-encoded acquisitions with inferior temporal resolution $=23 \mathrm{~ms}$ and echo-planar-imaging factor 11 at five locations (aortic valve, ascending and proximal descending aorta, diaphragm and above the bifurcation) (Figure 1). Aortic PWV-assessment was compared to the reference standard.

\section{Results}

MRI-results are presented in Table 1 and Figure 2. Despite inferior temporal resolution, 4-slice PWVmethod showed stronger correlation with the reference standard and less error and variation compared to 2 -slice method. Of note, 4-slice method also resulted in $75 \%$ scan time reduction.

\section{Conclusions}

4-slice breath-held through-plane velocity-encoded MRI at five locations perpendicular to the aorta improves PWV-assessment versus traditionally-used 2-slice freebreathing velocity-encoded MRI, despite inferior temporal resolution.

${ }^{1}$ Leiden University Medical Center, Leiden, Netherlands

Full list of author information is available at the end of the article

(c) 2011 Kröner et al; licensee BioMed Central Ltd. This is an open access article distributed under the terms of the Creative Commons 


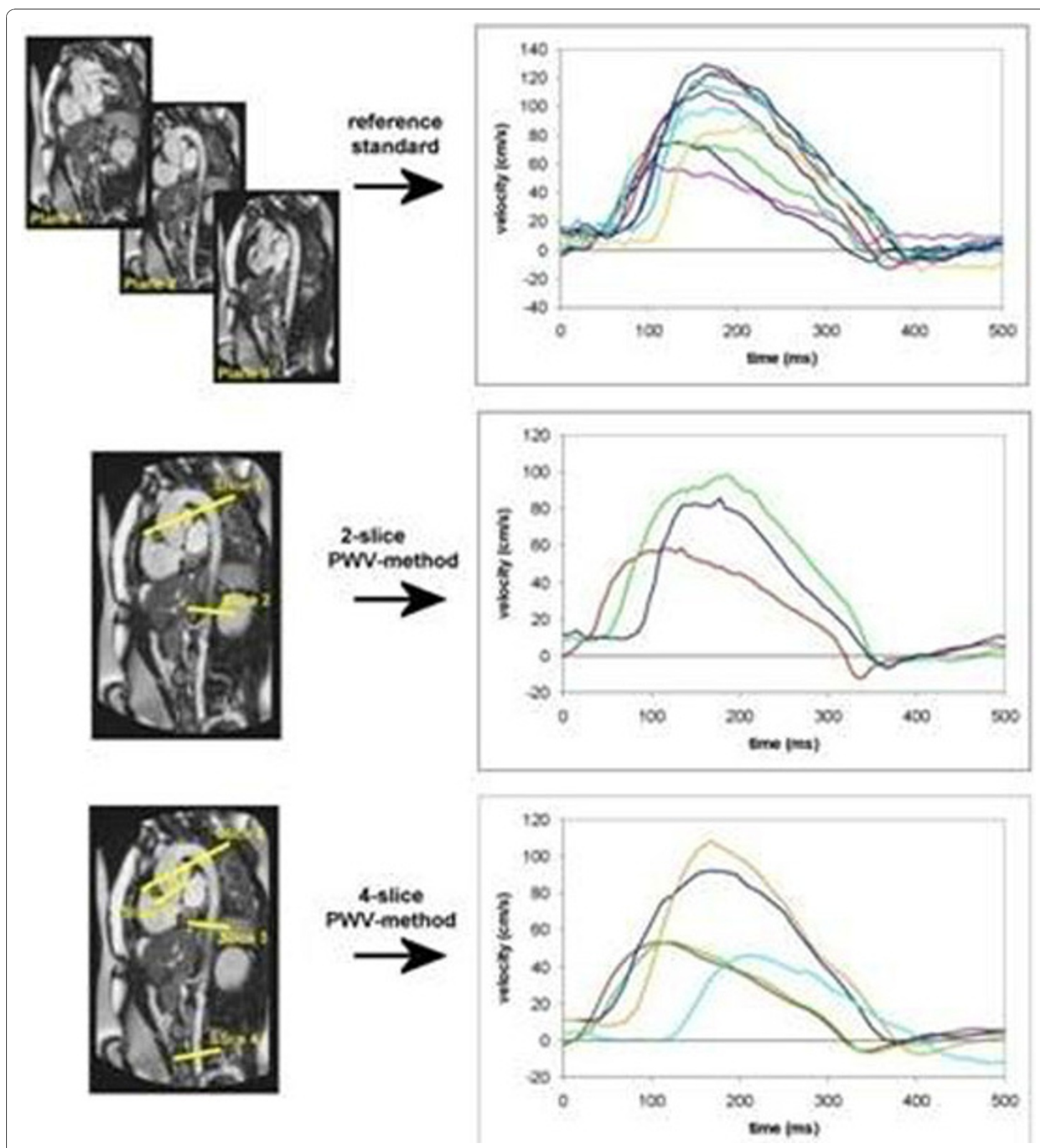

Figure 1 Methods for PWV-assessment: two-directional in-plane velocity-encoded MRI (reference standard), 2-slice free-breathing one-directional through-plane velocity-encoded MRI, 4-slice breath-held one-directional through-plane velocity-encoded MRI. PWV is determined from the systolic velocity wave front propagation. 
Table 1 MRI-results

\begin{tabular}{lll}
\hline & $\begin{array}{l}\text { PWV 2-slice } \\
\text { method }\end{array}$ & $\begin{array}{l}\text { PWV 4-slice } \\
\text { method }\end{array}$ \\
\hline $\begin{array}{l}\text { Pearson } r \\
\begin{array}{l}\text { Mean difference } \pm \text { standard } \\
\text { deviation (m/s) }\end{array}\end{array}$ & 0.47 & 0.82 \\
p-value t-test & $0.40 \pm 1.40$ & $0.18 \pm 0.56$ \\
Mean unsigned error & 0.24 & 0.19 \\
Coefficient of variation & $18 \%$ & $8 \%$ \\
Mean total scan time & $25 \%$ & $10 \%$ \\
\hline
\end{tabular}

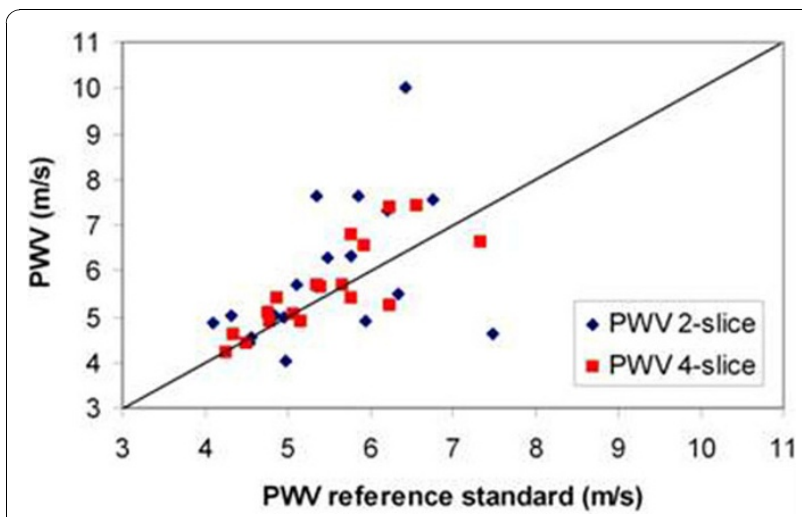

Figure 2 Correlation for 2-slice and 4-slice PWV-assessment with the reference standard.

\section{Acknowledgement}

Funding by the Netherlands Heart Foundation (Project 2006B138) is

gratefully acknowledged.

\section{Author details}

${ }^{1}$ Leiden University Medical Center, Leiden, Netherlands. ${ }^{2}$ Academic Medical

Center, Amsterdam, Netherlands.

Published: 2 February 2011

\section{References}

1. Westenberg, et al: JMRI 2010

2. Grotenhuis, et al: JMRI 2009.

doi:10.1186/1532-429X-13-S1-071

Cite this article as: Kröner et al:: Accuracy of aortic pulse wave velocity assessment with velocity-encoded MRI: validation in patients with Marfan syndrome. Journal of Cardiovascular Magnetic Resonance 201113

(Suppl 1):071.

Submit your next manuscript to BioMed Central and take full advantage of:

- Convenient online submission

- Thorough peer review

- No space constraints or color figure charges

- Immediate publication on acceptance

- Inclusion in PubMed, CAS, Scopus and Google Scholar

- Research which is freely available for redistribution

Submit your manuscript at www.biomedcentral.com/submit 